\title{
PENERAPAN ELEMEN ISM CODE UNTUK MENUNJANG KESELAMATAN PELAYARAN PADA KM PANTOKRATOR
}

\author{
Mika Patayang ${ }^{1)}$ dan Rakhel Lia ${ }^{2)}$ \\ ${ }^{1,2}$ Kemaritiman, Politeknik Negeri Samarinda. \\ 1,2J1 Batu Cermin Sempaja Ujung, Samarinda, 75119. \\ E-mail : m.patayang81@ gmail.com ${ }^{1)}$,rakhel.1@ gmail.com ${ }^{2}$
}

\begin{abstract}
ABSTRAK
Tingginya tingkat kecelakaan kapal merupakan indikasi perlunya perhatian terhadap penerapan system manajemen code pada sebuah perusahaan pelayaran. Oleh karena itu keselamatan dalam berlayar merupakan hal yang sangat penting dalam dunia pelayaran. Kenyamanan crew di atas kapal dalam beraktivitas sangat berpengaruh terhadap efektivitas kerja crew tersebut. Ada beberapa faktor yang dapat menyebabkan crew merasa nyaman dan aman berada diatas kapal, diantaranya kapal dan perlengkapannya harus dipelihara dan diusahakan selalu baik dan berfungsi dengan baik. Penelitian ini bertujuan untuk mengetahui apakah elemen pada ISM CODE khususnya elemen 10 tentang kapal dan perlengkapannya harus dipelihara dan diusahakan selalu baik dan berfungsi. Semua peralatan/perlengkapan yang penting bagi keselamatan harus selalu terpelihara dan diyakini akan berfungsi dengan baik melalui pengujian secara teratur/berkala. Pada penelitian ini menggunakan metode studi kasus dimana data diperoleh melalui observasi, wawancara terhadap crew kapal KM Pantokrator dan melakukan pemeriksaan terhadap dokumen yang berhubungan dengan elemen 10 (pemeliharaan kapal dan perlengkapannya) dimana kapal dan perlengkapannya harus dipelihara dan diusahakan selalu baik dan berfungsi, manajemen kapal harus selalu menaati semua ketentuan serta perlengkapan alat keselamatan harus memenuhi jumlah dan kondisi yang telah ditentukan sesuai dengan pada ISM CODE. Berdasarkan hasil penelitian ini diperoleh data bahwa pada KM Pantokrator telah menerapkan elemen 10 ISM CODE untuk menunjang keselamatan pelayaran berupa adanya kelengkapan alat keselamatan dan kondisi alat keselamatan yang berfungsi dengan baik, dokumen-dokumen berupa fire control plan, muster list, emergensi prosedur, nautikal publication, dan jadwal perawatan perlengkapan kapal. Dengan diterapkannya elemen 10 dari ISM CODE maka diharapkan keselamatan dalam pelayaran dapat ditingkatkan.
\end{abstract}

Kata Kunci: Keselamatan, Pelayaran ,Kapal, crew, Perusahaan, ISM CODE.

\section{PENDAHULUAN}

Peningkatan kesejahteraan hidup merupakan dambaan bagi pemerintah dan seluruh rakyat Indonesia. Hal ini dapat terwujud jika seluruh komponen aspek dapat dikembangkan dan di tingkatkan peranannya secara maksimal. Keberadaan Negara kita Indonesia yang merupakan negara kepulauan yang dihubungkan oleh laut maka keberadaan moda transportasi laut yaitu kapal merupakan hal yang sangat penting. Oleh karena itu pemerintah harus mampu membuat suatu regulasi agar keselamatan pelayaran dapat terwujud. Ketentuan dasar mengenai pelayaran tersebut telah diatur dalam UU No 17 Tahun 2008 tentang pelayaran nasional. Salah satu isi dari pasal-pasal UU No. 17 Tahun 2008 tentang pelayaran adalah keselamatan pelayaran. Keselamatan pelayaran yang dimaksud adalah kelaiklautan kapal (Utomo.dkk., 2017). Secara keseluruhan termasuk di dalam pasal 1 ayat 32 sampai ayat 44 UU no. 17 Tahun 2008, sementara pasal 1 ayat 34 khusus berisi keselamatan kapal yaitu keadaan kapal yang memenuhi persyaratan material, konstruksi, bangunan, permesinan dan perlistrikan, stabilitas, tata susunan serta perlengkapan termasuk perlengkapan alat penolong dan radio, elektronik kapal, yang dibuktikan dengan sertifikat setelah dilakukan pemeriksaan dan pengujian.
Keselamatan pelayaran itu ditentukan oleh banyak faktor, bukan hanya ditentukan oleh satu faktor saja. Misalnya kecanggihan kapal dan peralatan-peralatan modern yang melengkapinya namun juga sangat tergantung kepada berbagai faktor, seperti kemampuan sumber daya manusia, peralatan di darat, koordinasi yang dilaksanakan selama sebelum dan selama pelayaran berlangsung serta memperhitungkan rambu-rambu laut dan faktor penumpang sangat berperan untuk mewujudkan hal tersebut (Ar, 2015). Tingginya tingkat kecelakaan kapal mengakibatkan banyaknya kerugian yang ditimbulkan baik secara moril maupun materil, kerugian moril seperti banyaknya crew kapal dan penumpang yang tewas dalam kecelakaan kapal tersebut dan akibat kecelakaan kapal juga berdampak negatif terhadap ekosistem laut.

Akibat tingginya tingkat kecelakaan kapal mendorong pemerintah untuk membuat suatu regulasi yang diharapkan dapat mengurangi terjadinya kecelakaan kapal. Salah satu regulasi yang diterapkan bahwa setiap perusahaan pelayaran harus dapat menerapkan sistem ISM CODE dalam pengoperasian kapal (Kritis, Kapal and Pt, 2010). Penelitian ini dilakukan pada kapal penumpang KM Pantokrator, dimana kapal ini berlayar dari pelabuhan Samarinda-Kalimantan Timur menuju 
pelabuhan penumpang Pare-pare Sulawesi Selatan. Kapal ini melakukan pelayaran setiap minggu dengan kapasitas penumpang 1000-1760 orang. Untuk menjamin keselamatan crew dan penumpang maka kondisi kapal harus dipastikan laiklaut pada saat melakukan pelayaran dan alat keselamatan harus dalam keadan yang baik secara kualitas dan kuantitas. Diharapkan dengan diterapkannya elemen ISM CODE diatas kapal penumpang KM Pantokrator maka crew dan penumpang dapat merasa aman diatas kapal dan pelayaran dapat berjalan dengan baik (Terhadap and Kapal, 2015).

\section{RUANG LINGKUP}

Dalam penelitian ini permasalahan mencakup:

1. Cakupan permasalahan dalam penelitian ini yaitu meneliti tentang kelengkapan alat keselamatan di atas kapal dan kondisi alat keselamatan dipastikan dalam keadaan yang baik, dokumen prosedur dan jadwal perawatan kapal dan peralatannya, serta dokumendokumen keselamatan pada KM Pantokrator.

2. Pada penelitian ini hanya fokus meneliti pada penerapan elemen 10 dari ISM CODE mengenai alat keselamatan, jadwal dan prosedur perawatan serta dokumen keselamatan pada kapal KM Pantokrator .

3. Rencana hasil yang didapatkan dari penelitian ini adalah informasi tentang kelengkapan alat keselamatan, baik secara jumlah dan fungsinya berjalan dengan baik, dilakukannya prosedur perawatan serta memiliki dokumen-dokumen keselamatan, sehingga dari hasil penelitian ini dapat memberikan masukan kepada pihak yang berwenang agar kapal yang tidak menerapkan elemen 10 dari ISM CODE untuk tidak diberikan ijin berlayar.

\section{BAHAN DAN METODE}

Metode yang penulis digunakan dalam penelitian ini adalah studi kasus. Studi kasus yaitu mempelajari kasus tertentu pada obyek yang terbatas. Dalam hal ini adalah penerapan elemen 10 ISM CODE dikapal penumpang KM Pantokrator. Uraian hasil penelitian dilakukan secara deskriptif yaitu menguraikan hasil penelitian secara terinci dan sitematis. Kapal Penumpang KM Pantokrator yang menjadi objek penelitian adalah kapal penumpang yang memiliki rute dari pelabuhan Samarinda di Kalimantan Timur ke pelabuhan Pare-pare di Sulawesi Selatan yang melakukan pelayaran satu kali seminggu. Gross Tonnage: 5920 dan Length Overall x Breadth Extreme: $109.2 \mathrm{~m} \times 15.03 \mathrm{~m}$, serta kapasitas penumpang 1760 orang. Data penelitian diambil di kapal KM Pantokrator yang sedang sandar di pelabuhan Samarinda, dimana data diperoleh dengan melakukan observasi, wawancara terhadap crew dan melakukan pemeriksaan terhadap dokumen keselamatan kapal . Jenis dan sumber data yang digunakan dalam penelitian adalah kualitatif dan kuantitatif. Data dikumpulkan dalam bentuk tabel isian tentang ketersediaan dan kondisi alat keselamatan, jadwal dan prosedur perawatan, dan dokumen keselamatan pelayaran. Adapun data yang digunakan dalam penelitian adalah data primer dan data sekunder. Data primer adalah data yang diperoleh langsung melalui pengamatan. Data sekunder adalah data yang diperoleh dari perusahaan, dinas Perhubungan, dan studi pustaka mengenai jenis dan alat keselamatan yang digunakan di atas kapal KM Pantokrator.

\subsection{Keselamatan Pelayaran}

Keselamatan pelayaran Peraturan Safety Of Life At Sea (SOLAS) adalah peraturan yang mengatur keselamatan maritim paling utama dengan tujuan untuk meningkatkan jaminan keselamatan hidup di laut yang dimulai sejak 1914, mengingat saat itu banyak terjadi kecelakaan kapal yang menelan banyak korban jiwa (Pelabuhan and Perak, 2018). Pada tahap permulaan, dimulai dengan fokus pada peraturan kelengkapan navigasi, kekedapan dinding penyekat kapal serta peralatan berkomunikasi, kemudian berkembang pada konstruksi dan peralatan lainnya. Modernisasi peraturan SOLAS sejak 1960 adalah menggantikan Konvensi 191 dengan SOLAS 1960. Sejak saat itu, peraturan mengenai desain untuk meningkatkan faktor keselamatan kapal mulai dimasukan seperti: Desain konstruksi kapal, Permesinan dan instalasi listrik, Pencegah kebakaran, Alat-alat keselamatan, Alat komunikasi dan keselamatan navigasi. Adapun, usaha penyempurnaan peraturan tersebut dengan cara mengeluarkan peraturan tambahan (amandement) hasil konvensi IMO yang dilakukan secara berturut-turut pada 1966, 1967, 1971 dan 1973. Namun usaha untuk memberlakukan peraturan- peraturan tersebut secara internasional kurang berjalan sesuai dengan yang diharapkan, terutama karena hambatan prosedural, yaitu: diperlukannya persetujuan $2 / 3$ dari jumlah negara anggota untuk meratifikasi peratruran dimaksud, ternyata sulit dicapai pada waktu yang diharapkan. Selanjutnya pada rentang 1974, dibuat konvensi baru SOLAS 1974, yakni pada setiap amandemen diberlakukan sesuai target waktu yang sudah ditentukan, kecuali ada penolakan dari 1/3 jumlah negara anggota atau $50 \%$ dari pemilik tonnage yang ada di dunia(Rahman dkk., 2017). Beberapa fasilitas keselamatan yang terdapat diatas kapal meliputi:

1. Life Boy digunakan sebagai pelampung untuk penumpang apabila tetjadi kecelakaan, tersedia sebanyak 13 buah.

2. Life Jacket merupakan jaket pelampung yang dikenakan oleh setiap penumpang apabila dalam kondisi darurat kapal mengalami kecelekaan. Alat tersebut disediakan pada tiap -tiap ruang penumpang dengan jumlah sesuai dengan jumlah penumpang, untuk penggunaan alat terse but terlebih dahulu dilakukan peragaan cara penggunaan.

3. Fire Plant merupakan peta denah evakuasi keadaan darurat alat tersebut terdapat pada di dinding dan diletakan pada suatu tempat yang mudah terjangkau. 
4. Life raft berfungsi seperti sekoci yang digunakan dengan melempar kelaut dan akan mengembang, didalamnya terdapat oksigen.

5. Rakit dengan kapasitas untuk 12 orang sebagai alat angkut penumpang diatas air yang digunakan dalam kondisi darurat apabila terjadi kecelakaan kapal, alat tersebut, tersedia sebanyak 14 buah.

6. Sekoci merupakan perahu kecil yang dilengkapi dengan mesin motor, tersedia satu unit.

7. Top Deck (Muster station) merupakan tempat berkumpul/evakuasi penumpang pada keadaan darurat, tempat ini terdapat dilantai atas kapal dan merupakan ruang terbuka.

8. Alat pemadam kebakaran dan perlengkapannya.

9. Disamping beberapa fasilitas keselamatan yang telah disebutkan diatas, untuk mengamankan kendaraan diatas kapal dipasang suatu alat yang bemama Tali Lasing yang berguna unuk mengikat kendaraan terutama kendaraaan besar seperti truk agar tidak bergerak bila terjadi guncangan.

10. Diatas kapal disediakan pula tabung alat pemadam kebakaran bila diatas kapal terjadi kebakaran kecil, alat ini berjumlah 11 buah dan diletakan di beberapa tempat yang mudah terjangkau. (Santara ., 2014).

\subsection{ISM CODE}

ISM Code atau kependekan dari International Safety Management Code adalah standar internasional Sistem Manajemen Keselamatan untuk pengoperasian kapal secara aman dan usaha pencegahan pencemaran di laut. Tujuan dari penerapan ISM Code adalah menjamin keselamatan di laut untuk menghindari kecelakaan yang dapat menimbulkan korban jiwa serta kerusakan kapal yang dapat menimbulkan pencemaran lingkungan di laut. ISM Code merupakan produk IMO (International Maritime Organization) yang akhirnya diadopsi oleh SOLAS (Safety of Life at Sea) pada tahun 1994.(Rahman dkk., 2017) . Disamping persyaratan teknis dan non teknis, dalam manajemen keselamatan pelayaran ada beberapa persyaratan atau kelengkapan administrasi yang harus dipenuhi diantaranya : 1 . Dokumen Penyesuaian Manajemen Keselamatan ( Document Of Compliance ) Merupakan audit dari Sistem Manajemen Keselamatan Perusahaan yang telah memenuhi ketentuan dari Koda Manajemen Intemasional untuk Keselamatan Pengoperasian Kapal dan Pencegahan Pencemaran (ISM-Code), dokumen tersebut berlaku selama 5 ( lima) tahun dan wajib dilakukan verfikasi secara berkala setiap 1 (satu) tahun sekali. 2. Sertifikat Manajemen Keselamatan (Safety Man- agement Certificate ) Sertifikat Manajemen Keselamatan diterbitkan oleh Menteri Perhubungan berdasarkan Konvensi Intemasional tentang KeselamatanJiwa di Laut 1974, sertifikat diterbitkan setelah dikakukan audit Sistem Manajemen Keselamatan perusahaan yang telah memenuhi ketentuan dari Koda Manajemen Intemasional untuk
Keselamatan pengoperasian kapal dan Pencegahan Pencemaran ( ISM - Code ) 3. Sertifikat keselamatan Kapal Penumpang ( Passanger Ship Safety Certifikate ) Sertifikat Keselamatan Kapal Penumpang diterbitkan berdasarkan pemeriksaan teknis atas kelengkapankapal termasuk kelengkapan keselamatan yang harus tersedia diatas kapal berdasarkan ketentuan yang berlaku.(Kalu, Kaparang E and Modaso O J, 2017)

Ada 13 elemen yang tercantum dalam International Safety Management Code diantaranya:

1. Umum

2. Kebijakan Keselamatan dan Perlindungan Lingkungan

3. Tanggung jawab dan Wewenang Perusahaan

4. Designated Person

5. Tanggung jawab dan Wewenang Master

6. Sumber Daya dan Tenaga Kerja

7. Pengembangan Rencana Operasi Kapal

8. Kesiapan Menghadapi Keadaan Darurat

9. Pelaporan dan Analisa Non Conformity, Kecelakaan dan Kejadian Berbahaya

10. Pemeliharaan Kapal dan Perlengkapannya

11. Dokumentasi

12. Verifikasi, Tinjauan Ulang dan Evaluasi Perusahaan

13. Sertifikasi, Verifikasi dan Pengawasan.

Tujuan ISM Code adalah untuk menjamin keselamatan dilaut, mencegah kecelakaan dan hilangnya jiwa manusia serta menghindari kerusakan lingkungan khususnya lingkungan laut dan hilangnya harta benda. Penerapan ISM CODE pada semua pihak yang terlibat dalam proses pelayaran baik pemerintah, perusahaan dan lingkungan dan kesemuanya itu bersatu untuk menciptakan pelayaran yang aman sehingga keselamatan pelayaran dapat tercapai.(Safety and Code, 2014).

Beberapa alasan untuk menjalankan ISM Code yaitu: ISM Code menjadikan kapal sebagai tempat yang aman untuk bekerja;

1. ISM Code melindungi laut dan lingkungan/ wilayah perairan.

2. ISM Code mendefinisikan tugas secara jelas dan ISM Code adalah hukum.

3. Dengan diterapkannya ISM CODE di dunia pelayaran maka akan melindungi crew kapal, perusahaan dan lingkungan (Rahman $d k k$., 2017).

Kapal yang telah memenuhi persyaratan manajemen keselamatan dan pencegahan pencemaran dari kapal akan diberi sertifikat. Dalam pemenuhan persyaratan Sistem Manajemen Keselamatan akan diberikan sertifikat diantaranya dokumen Penyesuaian Manajemen Keselamatan (Document of Compliance/DOC) untuk perusahaan dan Sertifikat Manajemen Keselamatan (Safety Management Certificate/SMC) untuk kapal. Faktor yang sangat berperan dalam penerapan elemen ISM CODE adalah faktor pengawasan, dimana faktor pengawasan ada dua yaitu pengawasan internal meliputi Kualifikasi SDM Pengawas, Jumlah SDM pengawas, Cara Pengawasan, Anggaran Pengawasan, Prosedur Pengawasan Internal serta Peralatan pengawasan dan 
pengawasan external yang meliputi Kualifikasi SDM Pengawas, Prosedur Pengawasan External.(Anjas $d k k$, 2019).

\subsection{Perawatan Kapal}

Pengertian Perawatan adalah: "Memelihara kapal agar selalu dalam keadaan yang siap operasional dan dapat memenuhi jadwal pelayaran kapal yang telah ditentukan tepat pada waktunya".(Kapal and Ad, no date)". Perawatan adalah gabungan dari suatu kegiatankegiatan yang bertujuan untuk menjaga atau mengembalikan suatu peralatan menjadi seperti sediakala pada kondisi yang baik untuk dapat dipergunakan kembali. Lebih lanjut pengertian perawatan adalah suatu usaha kegiatan untuk merawat suatu materil atau mesin agar supaya materil atau mesin itu dapat dipakai secara produktif dan mempunyai umur yang lama. Menurut pasal 309 ayat (1) KUHD, "kapal" adalah semua alat berlayar, apapun nama dan sifatnya.(Utomo $d k k$., 2017). Termasuk didalamnya adalah: kapal karam, mesin pengeruk lumpur, mesin penyedot pasir, dan alat pengangkut terapung lainnya. Meskipun benda-benda tersebut tidak dapat bergerak dengan kekuatannya sendiri, namun dapat digolongkan kedalam "alat berlayar" karena dapat terapung/mengapung dan bergerak di air. Menurut Undang-Undang Nomor 17 Tahun 2008 tentang Pelayaran, "kapal" adalah kendaraan air dengan bentuk dan jenis tertentu, yang digerakkan dengan tenaga angin, tenaga mekanik, energi lainnya, ditarik atau ditunda, termasuk kendaraan yang berdaya dukung dinamis, kendaraan di bawah permukaan air, serta alat apung dan bangunan terapung yang tidak berpindah-pindah. Peraturan Pemerintah Nomor 47 Tahun 1857 mengenai 2 (dua) macam kapal laut, yaitu kapal laut biasa dan kapal niaga. "Kapal niaga ialah setiap kapal laut yang digerakkan secara mekanis dan yang digunakan untuk mengangkut barang dan/atau orang untuk umum dengan pungutan biaya. Untuk menjaga kapal agar dapat beroperasi maka perawatan kapal merupakan hal yang harus dilakukan. Pemeliharaan Kapal adalah kegiatan perawatan dan perbaikan kapal yang dilaksanakan sendiri atau pihak lain baik pada masa operasi atau diluar masa operasi kapal, dalam rangka mempertahankan kelayakan kapal sehingga dapat beroperasi secara maksimal. Para pemilik kapal pada saat ini dalam melakukan penjadwalan pemeliharaan kapal menggunakan sistem yang bernama Planned Maintenance System. (Oktalisa, Matondang and Ishak, 2013). Sistem perawatan dan pemeliharaan kapal terbagi atas dua yaitu

\section{Rencana Kerja Docking Repair}

Schedule docking repair disusun dan ditetapkan berdasarkan masa laku surat-surat kapal atau sesuai dengan ketentuan Badan Klasifikasi dan Pemerintah.

Sesuai regulasi schedule docking dilaksanakan setiap 2 tahun untuk Annual Survey dan setiap 5 tahun untuk Special Survey.
Owner Superitendant (OS) menyiapkan dan menyusun Rencana Kegiatan Pemeliharaan kapal atau Plan Maintenance System (PMS) berdasarkan informasi: a. Jenis Survey, b. Last docking report, c. Outstanding class recommendations, d. Due date class items. e. Informasi terakhir dari Ship Board Management. f. Kumpulan permasalahan dari running repair yang masih ada.

Perkiraan waktu pelaksanaan docking repair diperhitungkan secara cermat dan ditetapkan lama waktu pelaksanaannya dengan memperhatikan volume pekerjaan yang direncanakan.(Kapal and Ad, no date)

\section{Rencana Kerja Running Repair.}

Rencana kerja running repair, pemeliharaan kapal direncanakan berdasarkan pertimbangan: tidak mengganggu operasi kapal dan ketersediaan peralatan kerja, material/suku cadang serta tetap harus memperhitungkan waktu pelaksanaannya.

Pelaksanaan Running Repair ini diselesaikan berdasarkan Plan Maintenance System yang telah disusun dan ditetapkan.(Demmatacco $d k k, 2013$ )

Owner Superintendant (OS) bertanggung jawab atas kelancaran pelaksanaannya dan setiap saat berkordinasi dengan Bagian Pengadaan untuk memastikan material, peralatan maupun sparepart yang dibutuhkan telah tersedia sebelum pekerjaan Running Repair dilaksanakan. Tingkat kepentingan terhadap kualitas perawatan dan reparasi kapal yang paling berpengaruh berturut-turut adalah pekerjaan penggantian pelat pada lantai car deck dan ruang bawah car deck, pekerjaan penggantian pondasi, pekerjaan replating pada bagian lambung kapal, kemudian pekerjaan pada cleaning tangki serta pekerjaan pada as propeller, lalu pekerjaan penggantian sekat dan pekerjaan penggantian beam pada kapal.(Hidayah and Ahmadi, 2017).

Standar perawatan kapal terdiri atas 4 yaitu:

1) Standar perawatan/ pemeliharaan bagian dek.

2) Standar perawatan/ pemeliharaan bagian mesin.

3) Standar perawatan/ pemeliharaan bagian radio.

4) Standar perawatan/ pemeliharaan alat-alat keselamatan.(Terhadap and Kapal, 2015)

\section{PEMBAHASAN}

Dari hasil penelitian yang telah dilakukan di kapal KM PANTOKRATOR mengenai kelengkapan alat keselamatan dan berfungsi dengan baik, jadwal dan prosedur perawatan kapal dan perlengkapannya serta dokumen keselamatan. Kelengkapan alat keselamatan diatas kapal KM Pantokrator seperti yang ditunjukkan pada tabel 1, terlihat bahwa jumlah alat keselamatan diatas kapal berupa life jacket sebanyak 2000 buah, sedangkan kapasitas penumpang maksimal KM Pantokrator 1760. Menurut regulasi SOLAS Jumlah life jacket untuk anak-anak adalah $10 \%$ dari jumlah keseluruhan penumpang yang ada di kapal. (SOLAS Chapter III,Regulasi 7.2). Setiap kapal harus membawa life jacket tidak kurang dari 5\% dari jumlah personil yang ada di atas kapal. (SOLAS Chapter III,Regulasi 
22.2). Berdasarkan aturan diatas menunjukkan bahwa jumlah life jacket telah memenuhi aturan ISM CODE berdasarkan aturan dari SOLAS. (Terhadap and Kapal, 2015). Untuk jumlah life boy yang ada diatas kapal itu ditentukan berdasarkan panjang dari kapal tersebut menurut SOLAS regulasi 22.1 Life Boy (Pelampung Penolong) untuk kapal barang minimal 8 buah sedangkan untuk kapal penumpang tergantung dari panjang (p) kapal: p < $200 \mathrm{ft}$ minimal 8 buah, p $200 \mathrm{ft}$ s.d.400 ft minimal 12 buah, p $400 \mathrm{ft}$ s.d $600 \mathrm{ft}$ minimal 18 buah, p $600 \mathrm{ft}$ s.d.800 ft minimal 32 buah, dan p > $800 \mathrm{ft}$ minimal 32 buah.(Riantini and Subiyanto, 2017). Dari shippartikuler panjang KM Pantokrator 357,6 ft, maka jumlah life boy yang harus dimiliki KM Pantokrator minimal 12 buah dan pada tabel 1 jumlah life boy pada KM Pantokrator ada 12 buah. Adanya keberadaan alat pemadam api ringan merupakan salah satu bagian penting dalam menunjang keselamatan dalam pelayaran. Dari tabel 1 terlihat jumlah APAR (Alat Pemadam Api Ringan) di kapal KM Pantokrator 30 buah. Hal tersebut sudah sesuai dengan jumlah APAR yang harus dimiliki KM Pantokrator sebanyak 27 buah menurut Peraturan Menteri Tenaga Kerja Transmigrasi Nomor PER 04/MEN/1980, ketentuan-ketentuan pemasangan APAR satu dengan yang lainnya tidak boleh melebihi 15 meter (dengan kata lain jarak antar APAR 15 meter) dari luas bangunan yang akan dilindungi. Untuk hidran dilihat dari gross tonase (GT) dari kapal menurut SOLAS Chapter II-2, Regulasi 10.2, Kapal harus dilengkapi dengan pompa pemadam, fire mains, hydran dan hoses. Tekanan pada hidran untuk kapal passenger, lebih dari $4000 \mathrm{GT}=0.4 \mathrm{~N} / \mathrm{mm}^{2}$ dan urang dari $4000 \mathrm{GT} \Rightarrow 0.3 \mathrm{~N} / \mathrm{mm}^{2}$. Dari tabel 1 dapat dilihat bahwa tekanan hydran pada KM Pantokrator dengan GT 5920 sudah sesuai dengan ketentuan yaitu sebesar 0,4N/mm². (Riantini and Subiyanto, 2017)

Untuk dokumen keselamatan, manajemen KM Pantokrator telah melengkapi semua dokumen keselamatan yang telah dipersyaratkan. Karena dengan tidak lengkapnya dokumen keselamatan maka ijin berlayar dari kapal tidak akan diterbitkan oleh pihak yang berwenang yaitu syahbandar. Menurut UndangUndang Pelayaran no. 17 tahun 2008, kapal dinyatakan laik laut apabila sudah dilengkapi dengan sertifikat Keselamatan Kapal, sertifikat pencemaran dari kapal, sertifikat Garis Muat dan pemuatan, Gross Akta, Surat Laut/Pas Besar/Pas Kecil/Pas Sungai dan danau, sertifikat Manajemen Keselamatan dan Pencegahan Pencemaran dari Kapal serta Sertifikat Manajemen Keamanan Kapal yang sesuai dengan daerah pelayarannya. Dokumen keselamatan yang ada di kapal KM Pantokrator dapat dilihat pada tabel 2.

Untuk prosedur dan jadwal peawatan pada sebuah kapal merupakan hal yang sangat penting karena dengan adanya prosedur dan jadwal perawatan maka pekerjaan diatas kapal dapat di kontrol dan lebih efisien. Dalam SOLAS 1974/1978 Chapter II Part C, D, E, dengan jelas menegaskan bahwa semua kapal dari Negara IMO harus melaksanakan "Perawatan dan Perbaikan Mesin Kapal". Untuk setiap perawatan yang dilakukan diatas kapal setiap crew harus mengikuti SOP yang telah ada. Perawatan yang dilakukan dikapal KM Pantokrator meliputi perawatan harian, perawatan periodik, dan perawatan berkalah. Perawatan harian yang dilakukan meliputi pemeriksaan pada pipa-pipa, pemeriksaan dan pencatatan parameter (temperatur, tekanan, laju aliran) yang biasanya dilakukan pada mesin induk dan mesin bantu, perawatan terhadap sirkulasi air pendingin. Perawatan periodik adalah perawatan yang dilakukan menurut batas waktu yang ditentukan dan biasanya mengikuti petunjuk dari buku manual. Perawatan periodik ini biasanya dilakukan setiap 50-250 jam kerja. Adapun jenis-jenis perawatan periodik yang dilakukan dikapal KM Pantokrator adalah sebagai berikut :

1) Membersihkan saringan bahan bakar.

2) Membersihkan elemen saringan minyak pelumas

3) Penggantian minyak pelumas

4) Pemeriksaan air pendingin.

Perawatan setiap 500-1000 jam kerja, pmeriksaan dan perawatan yang dilakukan antara lain :

1) Mengganti elemen saringan bahan bakar

2) Mengganti elemen saringan oli

3) Periksa clearence katup kepala silinder.

Perawatan berkala adalah perawatan yang dilakukan secara teratur atau rutin diantaranya adalah :

1) Memeriksa minyak pelumas setiap kali sebelum mesin start.

2) Mengganti minyak pelumas sesudah dipakai 250 jam kerja, kecuali mesin yang masih baru atau selesai direparasi besar-besaran (over haul).

Penggantian minyak pelumas dilakukan setelah 60 jam pertama. Penggantian minyak pelumas dilakukan dangan terlebih dahulu membuang minyak pelumas yang lama dengan jalan membuka baut pembuangnya pada waktu motor masih panas atau setelah motor berhenti bekerja. Disamping itu minyak pelumas juga harus dikeluarkan dari dalam saringan dan pendingin minyak pelumas. Apabila diperlukan ganti kertas saringannya.dengan adanya jadwal perawatan yang telah dibuat maka regulasi perawatan diatas kapal dapat dilakukan dengan teratur sehingga seluruh komponen baik itu komponen mesin, komponen alat navigasi dan komponen alat-alat keselamatan dipastikan telah dilakukan perawatan sedangkan dengan adanya prosedur perawatan itu mengidentifikasi bahwa perawatan yang dilakukan terhadap komponen-komponen telah dilakukan dengan baik dan benar serta untuk lebih memudahkan mengontrol pekerjaan yang akan dilakukan selanjutnya. Jadwal dan prosedur perawatan pada kapal KM Pantokrator dapat dilihat pada tabel 3. 
Tabel 1 Daftar dan Jumlah Alat Keselamatan.

\begin{tabular}{|l|c|c|c|}
\hline \multirow{2}{*}{ Nama Alat } & \multirow{2}{*}{$\begin{array}{c}\text { jumlah } \\
\text { (buah) }\end{array}$} & \multicolumn{2}{|c|}{ kondisi } \\
\cline { 3 - 4 } & 2 & $\sqrt{ }$ & \\
\hline $\begin{array}{l}\text { Sekoci } \\
\text { Penyelamat }\end{array}$ & 2 & $\sqrt{ }$ & \\
\hline $\begin{array}{l}\text { Ring Life } \\
\text { Boy }\end{array}$ & 10 & $\sqrt{ }$ & \\
\hline Life Jaket & 2000 & $\sqrt{ }$ & \\
\hline $\begin{array}{l}\text { Inflatable } \\
\text { Life Raft }\end{array}$ & 40 & $\sqrt{ }$ & \\
\hline $\begin{array}{l}\text { Line } \\
\text { Throwing } \\
\text { Apparatus }\end{array}$ & 5 & $\sqrt{ }$ & \\
\hline Appar & 30 & $\sqrt{ }$ \\
\hline $\begin{array}{l}\text { Hydrant } \\
\left(0,4 \mathrm{~N} / \mathrm{mm}^{2}\right)\end{array}$ & 20 & & \\
\hline
\end{tabular}

\section{Tabel 2 Daftar Dokumen Keselamatan}

\begin{tabular}{|l|c|c|}
\hline \multirow{2}{*}{ Dokumen } & \multicolumn{2}{c|}{ Ketersediaan } \\
\cline { 2 - 3 } & ada & tidak ada \\
\hline $\begin{array}{l}\text { Sertifikat Keselamatan } \\
\text { Kapal }\end{array}$ & $\sqrt{ }$ & \\
\hline $\begin{array}{l}\text { Sertifikat pencemaran } \\
\text { dari kapal }\end{array}$ & $\sqrt{ }$ & \\
\hline Sertifikat Garis Muat & $\sqrt{ }$ & \\
\hline $\begin{array}{l}\text { Sertifikat Klas yang } \\
\text { terdiri dari Sertifikat } \\
\text { Lambung (Hull) }\end{array}$ & $\sqrt{ }$ & \\
\hline Fire Control Plan & $\sqrt{ }$ & \\
\hline Muster List & $\sqrt{ }$ & \\
\hline Emergensy Prosedur & $\sqrt{ }$ & \\
\hline Nautikal Publication & $\sqrt{ }$ & \\
\hline Jadwal perawatan & $\sqrt{ }$ & \\
\hline Mesin utama & $\sqrt{ }$ & \\
\hline Pompa-pompa & $\sqrt{ }$ & \\
\hline OWS & $\sqrt{ }$ & \\
\hline Fres water generator & $\sqrt{ }$ & \\
\hline Kompresor & $\sqrt{ }$ & \\
\hline Alat keselamatan & $\sqrt{ }$ & \\
\hline
\end{tabular}

Tabel 3 Daftar Prosedur Kerja

\begin{tabular}{|l|c|c|}
\hline \multirow{2}{*}{\multicolumn{1}{|c|}{ Dokumen }} & \multicolumn{2}{|c|}{ Ketersediaan } \\
\cline { 2 - 3 } & ada & tidak ada \\
\hline $\begin{array}{l}\text { Prosedur Perawatan } \\
\text { system pelumasan }\end{array}$ & $\sqrt{ }$ & \\
\hline $\begin{array}{l}\text { Prosedur perawatan dan } \\
\text { perbaikan mesin utama }\end{array}$ & $\sqrt{ }$ & \\
\hline $\begin{array}{l}\text { Prosedur perawatan dan } \\
\text { perbaikan mesin bantu }\end{array}$ & $\sqrt{ }$ & \\
\hline $\begin{array}{l}\text { Perawatan system bahan } \\
\text { bakar }\end{array}$ & $\sqrt{ }$ & \\
\hline $\begin{array}{l}\text { Perawatan dan perbaikan } \\
\text { pipa-pipa }\end{array}$ & $\sqrt{ }$ & \\
\hline $\begin{array}{l}\text { Perawatan system } \\
\text { pendinginan }\end{array}$ & $\sqrt{ }$ & \\
\hline $\begin{array}{l}\text { Prosedur dan perawatan } \\
\text { alat-alat navigasi. }\end{array}$ & $\sqrt{ }$ & \\
\hline $\begin{array}{l}\text { Prosedur dan perawatan } \\
\text { alat komunikasi }\end{array}$ & $\sqrt{ }$ & \\
\hline $\begin{array}{l}\text { Prosedur perawatan alat } \\
\text { keselamatan }\end{array}$ & $\sqrt{ }$ & \\
\hline $\begin{array}{l}\text { Prosedur perawatan dan } \\
\text { perbaikan alat pemadam } \\
\text { kebakaran }\end{array}$ & $\sqrt{ }$ & \\
\hline
\end{tabular}

\section{KESIMPULAN}

Dari hasil penelitian yang dilakukan pada kapal KM Pantokrator mengenai alat-alat keselamatan (baik dari jumlah dan berfungsi dengan baik), kelengkapan dokumen keselamatan pelayaran serta kelengkapan jadwal dan prosedur perawatan yang dipersyaratkan dapat disimpulkan bahwa penerapan elemen 10 ISM CODE tentang perawatan kapal dan perlengkapannya untuk menunjang keselamatan telah dilakukan dengan baik oleh seluruh crew kapal maupun dari pihak manajemen kapal KM Pantokrator.

\section{SARAN}

Penelitian selanjutnya diharapkan dapat melakukan penelitian untuk penerapan semua elemen yang ada dalam ISM CODE, khususnya pada kapal penumpang agar keselamatan dalam berlayar dapat ditingkatkan.

\section{DAFTAR PUSTAKA}

Anjas, G.dkk. (2019) 'Analisis Penerapan Keselamatan dan Kesehatan Kerja ( K3 ) Pada Kapal Penumpang di PT PELNI Semarang', (2), pp. 2-3.

Ar, H. M. T. (2015) 'PENCEGAHAN KECELAKAAN KAPAL KE TITIK NOL ( ZERO ACCIDENT )', 3.

Demmatacco, F. dkk. (2013) 'Optimalisasi Sistem Perawatan Dan Perbaikan Terencana Mesin Produksi Berdasarkan Analisis Keandalan Pada Pltd Hatiwe Kecil Kota Ambon', Jurnal Rekayasa Mesin, 4(2), pp. 141-146.

Hidayah, N. Y. and Ahmadi, N. (2017) 'Analisis Pemeliharaan Mesin Blowmould Dengan Metode RCM Di PT. CCAI', Jurnal Optimasi Sistem 
Industri, $16(2), \quad$ p. $167 . \quad$ doi: 10.25077/josi.v16.n2.p167-176.2017.

Kalu, Y., Kaparang E, F. and Modaso O J, V. (2017) 'Studi tentang kesehatan dan keselamatan kerja di atas kapal pole and line yang berpangkalan di Aertembaga Bitung', Ilmu dan Teknologi Perikanan Tangkap, 2(6), pp. 212-216.

Kapal, K. and Ad, T. N. I. (no date) 'Pemilihan variabel penentu perawatan permesinan kapal untuk menaikkan keandalan kapal tni ad 1', 1(2), pp. 123132.

Kritis, P., Kapal, P. and Pt, B. (2010) 'Analisis pengawasan..., Very Rastanto, FKM UI, 2010.'

Oktalisa, P., Matondang, N. and Ishak, A. (2013) 'Perancangan Sistem Perawatan Mesin Dengan Pendekatan Reliability Engineering Dan Maintenance Value Stream Mapping (MVSM) Pada PT XXX', Jurnal Teknik Industri USU, 3(1), pp. 52-56.

Pelabuhan, D. I. and Perak, T. (2018) 'Implementasi ism code pada kapal kapal di pelabuhan tanjung perak', pp. 11-24.

Rahman, H. dkk (2017) 'Determination of the Dominant Factor Cause of Ship Accidents in Tanjung Priok
Oleh : Korespondensi : dansville88@yahoo.com', I(3), pp. 277-284.

Riantini, R. and Subiyanto, L. (2017) 'Aplikasi Penentuan Jumlah dan Peletakan Lifeboat dan Liferaft pada Kapal Penumpang dan Kargo berdasarkan Ketentuan SOLAS', 1509, pp. 201208.

Safety, I. and Code, M. (2014) 'ISM Code'.

Santara, A. G. dkk. (2014) 'Peralatan Keselamatan Kerja Pada Perahu Slerek di PPN Pengambengan, Kabupaten Jembrana, Bali Safety Equipment On Slerek In Pengambengan Nusantara Fishing Port, Jembrana, Regency, Bali', Jurnal IPTEKS PSP, 1(1), pp. 53-68.

Terhadap, A. And Kapal, K. (2015) 'Volume I Nomor 1, April 2015 (Danny Faturachman, dkk.)’, I(April), pp. 14-21.

Utomo, H. Dkk. (2017) 'SIAPA YANG BERTANGGUNG JAWAB MENURUT HUKUM', pp. 57-76. 